\title{
Pattern of Utilization of Maternal Health Care Services in Qalyubia Governorate
}

\author{
Osama M. Wassif, Raneyah H. Afifi ,_Eman M. Araby, Hala A. Abed, Mai M. Anwar \\ Department of Public Health and Community Medicine, Faculty of Medicine, Benha \\ University, Benha, Egypt
}

Received: September, 2018 Accepted: December, 2018

\begin{abstract}
Background: Antenatal care is one of the most effective maternal health interventions for preventing maternal morbidity and mortality particularly in places where the general health status of the women is poor. In Egypt, there is overall increase in utilization of Maternal Health Services (MHS) but there is considerable variation between governorates. Objective: To determine utilization pattern of the antenatal care service (ANC) services in Qalyubia Governorate and factors that shaped it. Method: Comparative cross sectional study, conducted on 400 females attending two PHC facilities in Qalyubia Governorate from $1^{\text {st }}$ January to $31^{\text {th }}$ August 2017. Results: Females' perception of the importance of ANC was very high either urban or rural (99.5\%). Urban females attending ANC health units were younger, more educated, of higher social class than the rural females. Urban females depend on printed methods as a source of health information more than the rural ones. No significant difference between urban and rural women considering the number of live children but the rural females experienced more number of pregnancies. All urban (100\%) women started ANC visits as early as the $1^{\text {st }}$ trimester with more frequent visits than the rural females and the majority of them $(89.9 \%)$ obtain the services from private clinics. Considering barriers of utilization of ANC from the point of view of rural versus urban females, rural females considered unavailability of physician $(70.8 v s .25 .3 \%)$ or presence of male physician $(5.1 \%$ vs. $0.7 \%)$, lack of drugs $(19.1 \%$ vs. $0.7 \%)$ or expensive treatment $(6.7 \%$ vs. $0 \%)$, long waiting time $(19.6 \%$ vs. $2.7 \%)$ and difficult transportation $(4.5 \%$ vs. $0.7 \%)$ are the main barriers. Conclusion: The ANC utilization pattern was generally satisfactory. The utilization of PHC for ANC was limited. Much less factors could affect ANC utilization pattern among different women.
\end{abstract}

Key words: Antenatal care, utilization, pattern, Qalyubia \& Egypt.

Corresponding author: Eman M. Araby Email : Eman.attia@fmed.bu.edu.eg

\section{Introduction}

Maternal mortality is the death of a woman while pregnant or within 42 days of termination of pregnancy, irrespective of the duration and site of the pregnancy, from any cause related to or aggravated by the pregnancy or its management but not from accidental or incidental cause. ${ }^{1}$ According to United Nations maternal mortality estimates, Egypt has reduced its maternal mortality ratio to $33 / 100,000$ live births in 2015 compared to $45 / 100,000$ in $2013,55 / 100,000$ in $2008,75 / 100,000$ in 2000 and 120/100,000 in 1990. Regional differences are present, with MMR being lowest in urban governorates and highest in frontier governorates. ${ }^{2}$ Antenatal care is one of the most effective health interventions for preventing maternal 
morbidity and mortality particularly in places where the general health status of the women is poor. ${ }^{3}$ ANC utilization has increased since the introduction in 2002 of the WHO ANC model, known as focused ANC (FANC) or basic ANC, which is a goal orientated approach to delivering evidence-based interventions carried out at four critical times during pregnancy at $4^{\text {th }}$, $\left(6^{\text {th }}\right.$ or $\left.7^{\text {th }}\right)$, 8th and $9^{\text {th }}$ month. However, globally, during the period 2007-2014, only $64 \%$ of pregnant women attended the WHO-recommended minimum four contacts for ANC, suggesting that much more work needs to be done to address ANC utilization and quality. ${ }^{1}$ The new guidance increases the number of contacts from four to eight, the first contact in the first 12 weeks' gestation, with subsequent contacts taking place at 20,26,30,34,36, 38 and 40 weeks' gestation ${ }^{4}$ Eight or more contacts for ANC can reduce perinatal deaths by up to 8 per 1000 births when compared to 4 visits. ${ }^{5}$ Utilization of maternal health services (MHS) can be measured by many indicators as percentage of mothers who received any and regular ANC from a trained medical provider and who had at least one tetanus toxoid injection during the pregnancy, percentage of mothers whose last live birth was protected from neonatal tetanus, and percentage of births who were delivered by a skilled provider, who were born in a health facility, and who were delivered by caesarean section. ${ }^{6}$ In Egypt, there is overall increase in utilization of MHS but there is considerable variation between governorates. The highest rates are in urban Lower Egypt while the lowest rates are in rural Upper Egypt. ${ }^{6}$ On identifying barriers that prevent access to ANC, many studies found significant effects of ethnic identity, regions, rural-urban, education attainment, parity, age, marital status, cost (include the cost of supplies, medicine and transportation), religion, occupation, and family size and structure on women's decisions on ANC utilization.,8 Other determinants are related to health service characteristics" availability, accessibility, affordability" women's position in the household and the society, women's knowledge, attitudes, beliefs, and culture were also found to correlate with ANC usage. ${ }^{9,10}$ In Egypt, there were a several studies examined the extent of utilization of MHS, but it was either too old and need to be renewed ${ }^{11}$ or it was conducted in governorate of Upper Egypt ${ }^{12}$, so we cannot generalize the results. This study tried to identify the overall factors affecting the utilization of MHS nowadays in Qalyubia Governorate, focusing on ANC program as our tool for evaluation.

Research Questions: What is utilization pattern of the ANC services in Qalyubia Governorate? Is there a difference between their ANC perception and actual utilization? What are the factors that shaped their ANC utilization pattern?

The overall aim of this study is to enhance the utilization of ANC in Qalyubia governorate through providing the stakeholders with the necessary information.

\section{Method}

It was a comparative cross sectional study, conducted from $1^{\text {st }}$ January to $31^{\text {th }}$ August 2017 in two PHC facilities (Benha MCH center"urban" vs. Gamgra health unit "rural") and both belong to Benha district. This study was performed according to the following sequence: Sample size calculation: Epi info ${ }^{\mathrm{TM}}$ software, Version 3.4.3 was used to calculate the least required sample size at confidence level 99.9\% and population size 97374 women. Using the proportion of ANC utilization (90\%) among mothers obtained from Egypt demographic and health survey $2015^{13}$. The least number was 389. Sample size of 400 women was taken. Sampling:- 
The two centers were chosen from all PHC centers located in Benha district; due to their physical accessibility and high flow. Two days per week were chosen to visit the MCH centers, (Saturday or Sunday or Monday) to visit $\mathrm{MCH}$ in Banha city and (Tuesday, Wednesday or Thursday) to visit the health unit in Gamgra village. The researcher went to the medical center from 9 am to $1 \mathrm{pm}$. The first female was chosen randomly then every $5^{\text {th }}$ one (systematic random technique) and so on till the sample size was completed. The researcher met with females after having the required service from the center (whether antenatal care , using of family planning methods, vaccinations and other services offered by $\mathrm{MCH}$ centers). The interview was for a period not exceeding ten minutes so it was suitable to choose every fifth woman in order to give the opportunity and enough time to ask females. The purpose of the study was mentioned to females and an oral consent was obtained before starting the interview. Constructing the questionnaire: A pre tested structured validated questionnaire form was used to collect data from the studied women ${ }^{14}$.The questionnaire was prepared and designed in a slang Arabic language, to ensure that all the interviewed women will be able to understand and answer it exactly. It asked about Socio- demographic characteristics: El- Gilany Social score was used to assess the socioeconomic status (SES) of the included females .The final scale included 7 domains with a total score of 84. SES was classified into four levels depending on the quartiles of the score calculated: those with score range from 1-21(very low social class), from 2242(low), from 43- 63(middle) and from 64 -84 (high social class). ${ }^{15}$ Current obstetric history: Number of pregnancies, Women perception about ANC services: Women were asked about degree of importance \& usefulness of ANC services. Pattern of utilization of the ANC service: females were asked if they utilized ANC service in the latest completed pregnancy or not, utilized the ANC service in previous pregnancies or not (only in multipara), time of their first ANC visit, frequency of their ANC visits. Barriers for attendance at PHC facilities: Like lack of enough services, unavailability of the specialists, unavailability of drugs, long waiting time, expensive treatment, presence of male physicians and long distance. Sources of information for seeking ANC Information: Mother, friends, mass media\& her ownself. Sources of encouragement for seeking ANC: Husband, mother, mother in law \& herself.

Pilot study: A pilot study was conducted to test the questionnaire and evaluate the interviewer performance. The results of pilot study was not involved in the final study results.

Data collection: Each interviewed woman was comfortably seated and the objectives of the study were explained to her to motivate her to give accurate answers. About 4 to 6 attendant women were interviewed per day. It took about $10-15$ minutes per respondent to complete the interview form.

Data Management:The collected sheets were divided into two groups each of (200 sheets). One researcher was responsible of one group for easier, faster and more accurate data entry, and this was done according to pre-determined code. Data were tabulated, coded and analyzed using the Statistical Package for the Social Sciences (SPSS) software version 20.0 for Windows. Qualitative data were expressed in number and percentage. The statistical difference was assessed with student $\mathrm{t}$ test \& Chi square test $\left(X^{2}\right) . \mathrm{P}$ value $<0.05$ was considered significant.

\section{Ethical approval:}

Approval from ethical committee of Benha faculty of medicine and head of (Table 1 ) 
: The socio-demographic characteristic of the studied groups :

\begin{tabular}{|c|c|c|c|c|}
\hline Items & $\begin{array}{c}\text { Urban(167) } \\
\text { No. }(\%) \\
\end{array}$ & $\begin{array}{c}\text { Rural(233) } \\
\text { No. (\%) }\end{array}$ & $\mathrm{X}^{2}$ & $\begin{array}{c}P \text { - } \\
\text { value }\end{array}$ \\
\hline \multicolumn{5}{|l|}{ 1-Education domain } \\
\hline Mother 's education & & & \multirow{4}{*}{125.3} & \multirow{4}{*}{$\leq 0.05$} \\
\hline Illiterate & $6(3.6)$ & $27(11.6)$ & & \\
\hline Educated & $22(13.2)$ & $144(61.8)$ & & \\
\hline Highly educated & $139(83.2)$ & $62(26.6)$ & & \\
\hline \multicolumn{5}{|l|}{ Husband 's education } \\
\hline Illiterate & $5(3)$ & $20(8.6)$ & \multirow{3}{*}{136.1} & \multirow{3}{*}{$\leq 0.05$} \\
\hline Educated & $24(14.4)$ & $158(67.8)$ & & \\
\hline Highly educated & $138(82.6)$ & $55(23.6)$ & & \\
\hline \multicolumn{5}{|c|}{ 2- Family Domain } \\
\hline \multicolumn{5}{|l|}{ No. of family members } \\
\hline$<5$ & $122(73.1)$ & $155(66.5)$ & \multirow{2}{*}{1.9} & \multirow{2}{*}{$>0.05$} \\
\hline$\geq 5$ & $45(26.9)$ & $78(33.5)$ & & \\
\hline \multicolumn{5}{|l|}{ Earning family members } \\
\hline 1 & $45(26.9)$ & $142(60.9)$ & \multirow{3}{*}{$\mathrm{FET}^{*}=49.5$} & \multirow{3}{*}{$\leq 0.05$} \\
\hline 2 & $119(71.3)$ & $83(35.6)$ & & \\
\hline 3 & $3(1.8)$ & $8(3.5)$ & & \\
\hline \multicolumn{5}{|l|}{ Educational level of children } \\
\hline All go/ went to school & $167(100)$ & $174(74.6)$ & \multirow{4}{*}{49.6} & \multirow{4}{*}{$\leq 0.05$} \\
\hline$<50 \%$ go /went to school & $0(0.0)$ & $12(5.2)$ & & \\
\hline$\geq 50 \%$ go /went to school & $0(0.0)$ & $12(5.2)$ & & \\
\hline None go /went to school & $0(0.0)$ & $35(15)$ & & \\
\hline \multicolumn{5}{|c|}{ 3-Occupation domain } \\
\hline Mother's work & & & & \\
\hline House wife & $44(26.3)$ & $135(57.9)$ & & \\
\hline Skilled worker & $2(1.2)$ & $16(6.9)$ & 55.25 & $\leq 0.05$ \\
\hline Employee/specialist & $121(72.5)$ & $82(35.2)$ & & \\
\hline Husband's work & & & & \\
\hline Not working & $1(0.6)$ & $18(7.8)$ & & \\
\hline Skilled worker & $19(11.4)$ & $104(44.6)$ & 69.98 & $\leq 0.05$ \\
\hline Employee/specialist & $147(88)$ & $111(47.6)$ & & \\
\hline & 4-Econo & ain & & \\
\hline Family income & & & & \\
\hline We borrow on it & $8(4.8)$ & $24(10.3)$ & & \\
\hline Just enough for usual needs & $33(19.8)$ & $161(69.1)$ & 149.9 & $\leq 0.05$ \\
\hline Can face emergencies & $51(30.5)$ & $44(18.9)$ & & \\
\hline Enable saving /investment & $75(44.9)$ & $4(1.7)$ & & \\
\hline & 5- Family po & domain & & \\
\hline Score & & & & \\
\hline $1-4$ & $6(3.6)$ & $27(11.6)$ & & \\
\hline $5-8$ & $22(13.2)$ & $144(61.8)$ & 125.3 & $\leq 0.05$ \\
\hline $9-12$ & $139(83.2)$ & $62(26.6)$ & & \\
\hline & 6- Home sa & domain & & \\
\hline Type of home & & & & \\
\hline Owned and $\geq 4$ rooms & $6(3.6)$ & $61(26.2)$ & & \\
\hline Owned and $<4$ rooms & $113(67.7)$ & $132(56.7)$ & $\mathrm{FET}^{*}=41.6$ & $\leq 0.05$ \\
\hline Rented and $\geq 4$ rooms & $2(1.2)$ & $7(3.0)$ & & \\
\hline Rented and <4 rooms & $46(27.5)$ & $33(14.2)$ & & \\
\hline Crowding index & & & & \\
\hline$\leq$ one to each room & $63(37.7)$ & $94(40.3)$ & 0.28 & $>0.05$ \\
\hline$>$ one to each room & $104(62.3)$ & $139(59.7)$ & & \\
\hline 7- Health care domain & & & & \\
\hline Sources of health services & & & & \\
\hline Private health care services & $125(74.9)$ & $38(16.3)$ & & \\
\hline Health insurance & $0(0.0)$ & $16(6.9)$ & & \\
\hline Free governmental services & $19(11.3)$ & $79(33.9)$ & 140.7 & $<0.001$ \\
\hline More than one choice & $23(13.8)$ & $97(41.6)$ & & \\
\hline I take the usual treatment & $0(0.0)$ & $3(1.3)$ & & \\
\hline
\end{tabular}

MCH and Gamgara health unit was obtained before the beginning of the study. Also verbal consent was taken from

females who approve to participate in the study. 


\section{Results}

This study included 400 females (167 belonged to the urban community of Benha city and 233 belonged to the rural community of Gamgara village). Females with the age range of (19 to less than 39 years) were more from urban community than the rural one $(94.6 \%$ vs. $77.3 \%)$, but those aged $(\geq 39$ years) were more from rural community (22.7\% vs. 5.4\%).

Socio-demographic characteristic of studied groups: Education domain: Urban women and their husbands were highly educated than the rural couples $(83.2 \% \& 82.6 \%$ vs. $26.6 \% \& 23.6 \%$ ) and these differences were statistically significant.

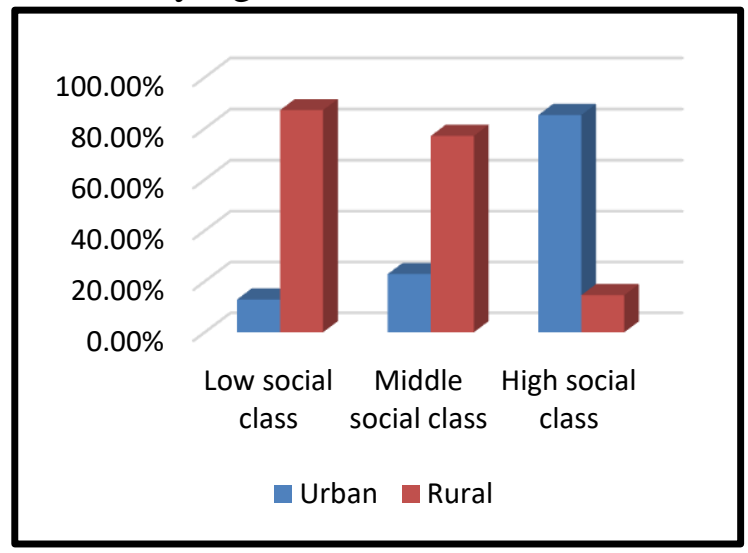

Figure (1): Socioeconomic class of the studied group

Family domain: No significant difference between urban \& rural females as regards number of family members. The majority of urban families has more than one earning member $(73.1 \%$ vs. 39.1 for rural females) and all urban children go/went to school vs. $(74.6 \%)$ of rural families and this was statistically significant. Occupation domain: the majority of urban couples $(72.5 \%$ for females \& $88 \%$ for males) were either employees or specialist and these percentages were significantly higher than rural couples (35.2\% \& 47.6\%). Economic domain: urban families were of higher income than the rural ones. About $45 \%$ of urban families can save and invest from their monthly income, while $69 \%$ of rural families have monthly income just sufficient to meet their usual needs

Family possessions domain: (refrigerator, radio, television, washing machine, telephone/mobile phone, car, agricultural land, non-agricultural land for housing, shop or animal shed, other house, animals/ poultry, computer/Internet) 1 point for the presence of each of items. Urban families achieve higher scores than rural ones and this was statistically significant.

Home sanitation domain: (26.2\%) of rural families have their Own house with $\geq 4$ rooms vs. only $(3.6 \%)$ of urban ones, but the crowding index was nearly the same in urban and rural houses.

Health care domain: About $(75 \%)$ of urban females receive their health care from private sector vs. (16.3\%) of rural females and about 34\% of rural females depend on Free governmental services (Table 1).

The overall socio-economic class revealed higher social class of urban ones (Figure 1).

Current obstetric history: women who had 4 or more pregnancies constituted higher percentage in rural community $(24.9 \%) v s .(11.4 \%)$ of urban $(\mathrm{p} \leq 0.05)$.

Women perception about ANC services: ANC was considered as a very important service from urban female point of view $(85.6 \%) v s .(67.4 \%)$ of rural women and the difference was of statistically significant importance $(\mathrm{p} \leq 0.05)$.

Pattern of utilization of the ANC service: All the studied urban and rural women utilized ANC during their previous pregnancies with no statistical significant difference, all urban women and $98.3 \%$ of rural women utilized ANC during their last pregnancy with no statistical significant difference. Urban women started ANC earlier than rural ones $\left(100 \%\right.$ in the $1^{\text {st }} 3$ months of pregnancy $v s . \quad 72 \%$ of rural 
Table (2): Comparison between urban and rural regarding utilization of antenatal care among female participants:

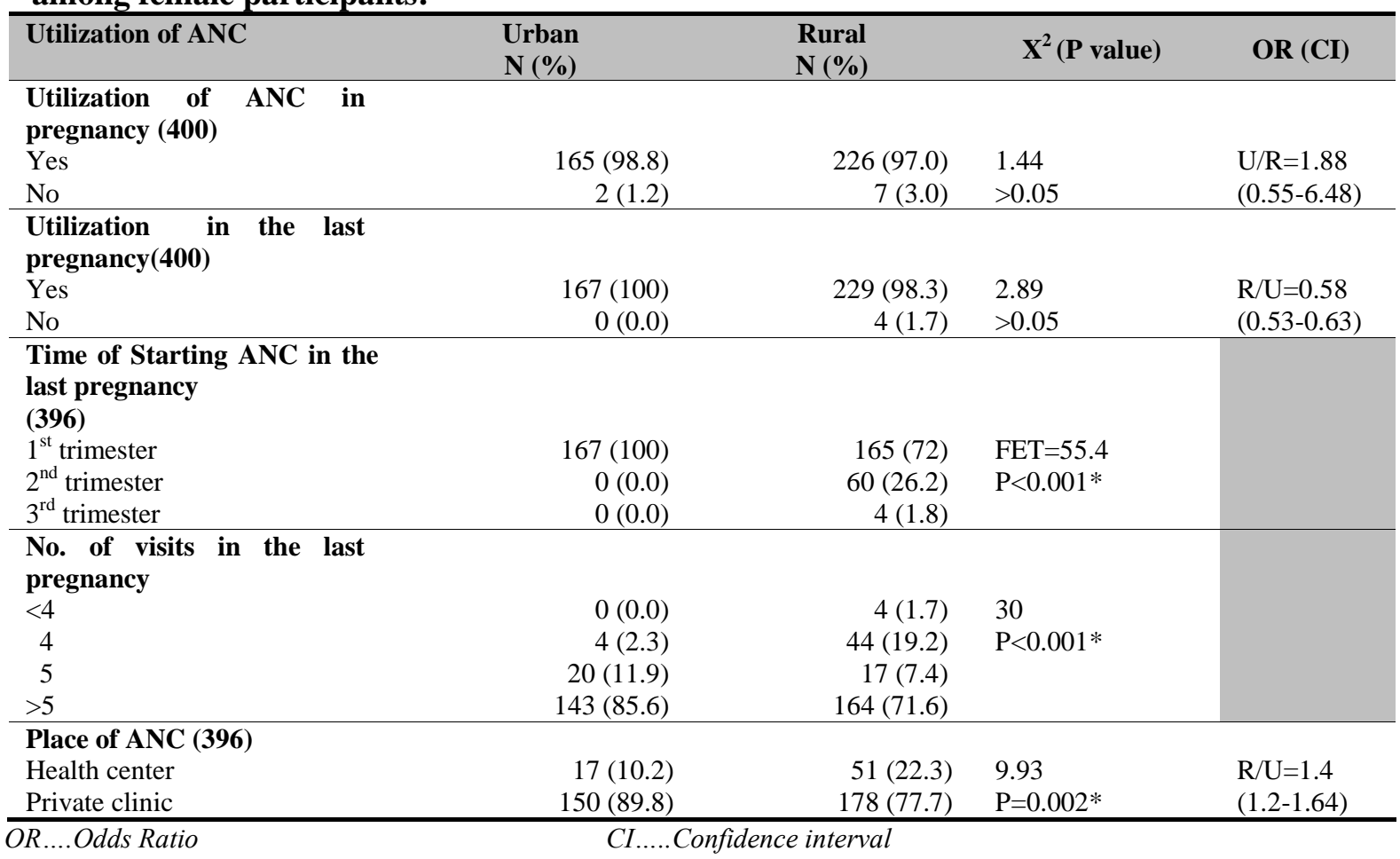

Table (3): Barriers of utilization of PHC services

\begin{tabular}{|c|c|c|c|c|}
\hline Barriers & $\begin{array}{c}\text { Urban } \\
\text { No. }=150(\%)\end{array}$ & $\begin{array}{c}\text { Rural } \\
\text { No. }=178(\%)\end{array}$ & $\begin{array}{c}\mathrm{X}^{2} \\
\text { (P value) }\end{array}$ & $\overline{\mathrm{OR}(\mathrm{CI})}$ \\
\hline $\begin{array}{l}\text { No enough services } \\
\text { Yes } \\
\text { No }\end{array}$ & $\begin{array}{r}143(95.3) \\
7(4.7)\end{array}$ & $\begin{array}{r}155(87.1) \\
23(12.9)\end{array}$ & $\begin{array}{l}6.67 \\
\left(\leq 0.05^{*}\right)\end{array}$ & $\begin{array}{l}\mathrm{U} / \mathrm{R}=2.057 \\
(1.06-3.97)\end{array}$ \\
\hline $\begin{array}{l}\text { Long waiting time } \\
\text { Yes } \\
\text { No }\end{array}$ & $\begin{array}{r}4(2.7) \\
146(97.3)\end{array}$ & $\begin{array}{r}30(16.9) \\
148(83.1)\end{array}$ & $\begin{array}{l}17.6 \\
(\leq 0.05 *)\end{array}$ & $\begin{array}{l}\mathrm{R} / \mathrm{U}=1.75 \\
(1.48-2.07)\end{array}$ \\
\hline $\begin{array}{l}\text { Unavailability of physicians } \\
\text { Yes } \\
\text { No }\end{array}$ & $\begin{array}{r}38(25.3) \\
112(74.7) \\
\end{array}$ & $\begin{array}{r}126(70.8) \\
52(29.2) \\
\end{array}$ & $\begin{array}{l}67.3 \\
(\leq 0.05 *)\end{array}$ & $\begin{array}{l}\mathrm{R} / \mathrm{U}=2.42 \\
(1.9-3.08)\end{array}$ \\
\hline $\begin{array}{l}\text { Unavailability of drugs } \\
\text { Yes } \\
\text { No }\end{array}$ & $\begin{array}{r}1(0.7) \\
149(99.3)\end{array}$ & $\begin{array}{r}34(19.1) \\
144(80.9)\end{array}$ & $\begin{array}{l}29.02 \\
(\leq 0.05 *)\end{array}$ & $\begin{array}{l}\mathrm{R} / \mathrm{U}=1.98 \\
(1.7-2.25)\end{array}$ \\
\hline $\begin{array}{l}\text { Long distance } \\
\text { Yes } \\
\text { No }\end{array}$ & $\begin{array}{r}2(1.3) \\
148(98.7)\end{array}$ & $\begin{array}{r}9(5.1) \\
169(94.9)\end{array}$ & $\begin{array}{l}\text { FET }=5.3 \\
\left(\leq 0.05^{*}\right)\end{array}$ & $\begin{array}{l}\mathrm{R} / \mathrm{U}=1.54 \\
(1.14-2.06)\end{array}$ \\
\hline $\begin{array}{l}\text { Difficult transportation } \\
\text { Yes } \\
\text { No }\end{array}$ & $\begin{array}{r}1(0.7) \\
149(99.3)\end{array}$ & $\begin{array}{r}8(4.5) \\
170(95.5)\end{array}$ & $\begin{array}{l}\mathrm{FET}=4.5 \\
\left(\leq 0.05^{*}\right)\end{array}$ & $\begin{array}{l}\mathrm{R} / \mathrm{U}=1.66 \\
(1.29-2.15)\end{array}$ \\
\hline $\begin{array}{l}\text { Expensive treatment } \\
\text { Yes } \\
\text { No }\end{array}$ & $\begin{array}{r}0(0.0) \\
150(100)\end{array}$ & $\begin{array}{r}12(6.7) \\
166(93.3)\end{array}$ & $\begin{array}{l}10.49 \\
(\leq 0.05 *)\end{array}$ & $\begin{array}{l}\mathrm{R} / \mathrm{U}=1.9 \\
(1.7-2.11)\end{array}$ \\
\hline $\begin{array}{l}\text { Presence of male physicians } \\
\text { Yes } \\
\text { No }\end{array}$ & $\begin{array}{r}1(0.7) \\
149(99.3)\end{array}$ & $\begin{array}{r}9(5.1) \\
169(94.9)\end{array}$ & $\begin{array}{l}3.5 \\
(>0.05)\end{array}$ & $\begin{array}{l}\mathrm{R} / \mathrm{U}=1.69 \\
(1.34-2.13)\end{array}$ \\
\hline
\end{tabular}


women) and the results were statistically significant. Urban women had more visits $(\geq 5)$ during their last pregnancy than the rural ones (97.6\%) vs. (79\%) and the difference was statistically significant. Studied women who attended their ANC at health center constituted $(22.3 \%)$ of rural group vs. $(10.2 \%)$ of urban one and this was statistically significant (Table 2).

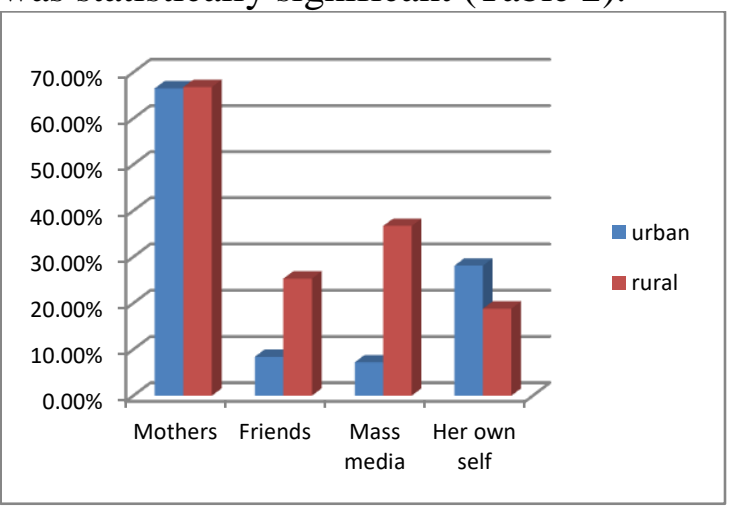

Figure (2): Sources of information for seeking ANC

Barriers of utilization of PHC services in women who didn't attend ANC: There was significant difference between urban and rural women who did not attend ANC at PHC centers regarding their causes of un-utilization. Lack of enough services followed by unavailability of the specialists were the main causes for urban and rural females $(95.3 \%$ \& $25.3 \%$ vs. $78.1 \% \& 70.8 \%$ respectively) and these differences were statistically significant .Rural females had other causes like unavailability of drugs (19.1\%),long waiting time $(16.9 \% \quad)$, expensive treatment $(6.7 \%)$, presence of male physicians $(5.1 \%)$ and long distance (5.1\%).All previously mentioned causes were significantly higher in rural community if compared with those of urban one (Table 3).

Sources of information for seeking ANC: Regarding the source of information about ANC, about $66 \%$ of both groups depended on mothers as a source of information ,but rural women significantly differed than urban females and they depended also on friends $(25.3 \%$ vs. $8.4 \%)$ \& media $(36.7 \%$ vs. $7.2 \%)$ as another sources of information (Figure 2).

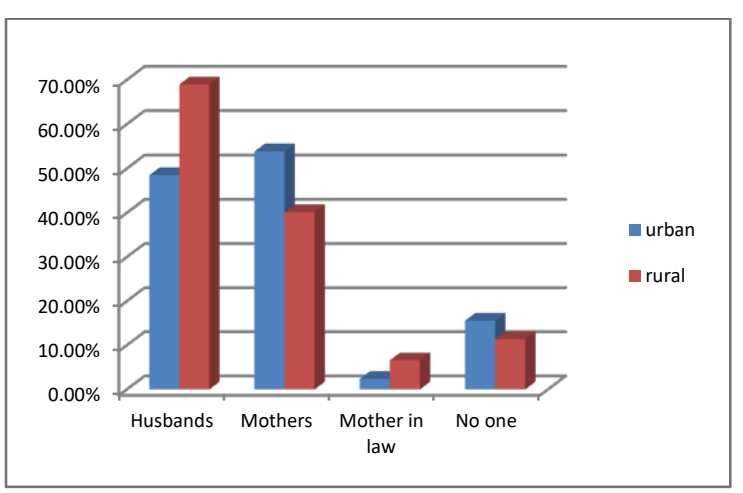

Figure (3): Sources of encouragement for seeking ANC

Sources of encouragement for seeking ANC: regarding persons who encouraged females for seeking ANC, there was significant difference between urban and rural women. Rural women were encouraged mainly by their husbands $(69 \%)$ while urban women were mainly encouraged by their mothers (53.9\%).Mothers in law had more supportive role in rural community than urban one $(6.6 \% \quad v s .2 .4 \%)$ and this was statistically significant (Figure 3).

\section{Discussion}

This study illustrated that women aging from 19 to less than 39 years were more likely to utilize ANC if compared to those aging $\geq 39$ Ys. This is may be due to that the elderly women particularly in urban areas may find it embarrassing to have a child in such relatively old age and/ or seem careless or even depressed to have such pregnancy that is commonly unplanned and unwanted. Our finding come in consistency with Pandey and Karki , 2014 ${ }^{16}$ who found that lower age group were more likely to have 
ANC services for more than four times than the women in higher age group ${ }^{16}$. Also, we found that women and their Partners' education is an influential factor on utilization of ANC in both urban and rural areas. Similar studies in India ${ }^{17}$ and Nigeria ${ }^{18}$ confirmed our findings and this could reflect the importance of education in raising the perception of people about the value of seeking health care. Another important factor that shapes utilization pattern of ANC is female's employment. Working women especially in the governmental sector are more likely to utilize ANC due to the earned health benefits from insurance coverage and she has financial autonomy than non-working woman. Graner et al.; $2010{ }^{19}$ and Malqvist et al.; $2010^{20}$ found the same results, but Hamed, $2014{ }^{21}$ in Egypt found that nonworking women were five times more likely to utilize ANC than working women in their latest completed pregnancy and this could be explained by the fact that not working women may have relatively more spare time and less busy.

This study revealed high utilization rate of ANC services among both urban and rural females and the possible explanation may be better awareness about ANC importance and its impact among low socioeconomic levels in Egypt. Urban females were of higher social class and this was reflected on seeking private clinics more than rural ones. This comes in agreement with Gupta et al. $2017^{22}$ who found that women in families with high income were more likely to receive ANC services than the women in the families with low income. This could be explained by the fact that as the socio-economic level increase, the awareness and care seeking behavior also increase so the women seek ANC caring for themselves and their babies also. Our results revealed that women who had $\leq 2$ child (both urban and rural) are more likely to utilize ANC and this was inconsistent with a study done in Nigeria by Babalola, 2012 who found that the number of living children was associated with antenatal care use in the urban areas but not in rural areas ${ }^{23}$. The possible explanation is that the mothers in Egypt whether urban or rural cares more about themselves whatever the number of children they have and this reflects the awareness of the Egyptian mothers about the importance of care seeking during pregnancy. Other studies ${ }^{24,25}$ showed that women with fewer number of children prefer to use ANC services. Regarding the proper time of registration for ANC (time of $1^{\text {st }}$ ANC visit), urban female started ANC much earlier and attended ANC visits more frequently than the rural one. This could be attributed to the qualitative and quantitative differences between urban and rural communities, not only in the characteristics of women and their household but also in the general context of the two settings. Most of the study women from both groups were covered by ANC in their latest completed pregnancy. Other study in Beni-Suef governorate in Egypt done by El Shirbiny et al. $2009^{26}$ found different results than ours and this may be because of better education and health services of Lower Egypt governorates than Upper Egypt. The majority of women from both groups utilized the private clinics for ANC but urban females were more than rural ones. Roy et al.; $2013^{27}$ agreed with our findings but another study conducted in Pakistan showed that rural women are mainly dependent on government's PHC health facilities for ANC. ${ }^{28}$ The most frequent factors in our results for not attending ANC at governmental health centers / units were the lack of enough care and services 
in the PHC, unavailability of specialists. Some women reported that the presence of male physicians and absence of female physicians, long waiting time, unavailability of drugs, long distance and difficult transportation were also reasons for not attending at the governmental services. Several studies came in agreement with our results like that of Isatou et al.; 2012 and Emelumadu et al.; 2014. ${ }^{29,30}$ Unlike previous studies 31,32 which focused on the motivation provided by husband in utilization of ANC care, this study considered the motivation by other family members and we found that not only the husbands who can encourage the women to utilize the ANC but also their mothers and mothers in law especially in rural community play an important role. Finally, although this study included women from different ages, social classes, but its results may not necessarily be generalized to represent the entire women using ANC in Qaluybia governorate or other area in Egypt. It could serve as a pilot study for other researches planned in a way that will ensure representativeness regarding; a bigger sample size, technique of participants selection, as well, more data collection.

\section{Conclusion:}

A satisfactory ANC utilization was observed regarding the initiation and frequency of ANC visits but there is limited utilization of PHC by the study women for ANC. Female' age, education, working condition, residence, family support and autonomy are an important factors that determine utilization of ANC services.

Recommendations: Policy-makers should consider educational, regulatory, financial,and personal and professional support interventions to recruit and retain qualified health workers in PHC centers especially in rural and remote areas. Provision of low cost ANC \&normal delivery services in PHC centers will encourage females to make benefits of these services especially if it is compared with very high cost of private sector. Health education through mass media about importance of ANC \& services should be provided by PHC centers like TT vaccination \& dietary supplementations to increase the overall utilization of ANC services.

\section{References:}

1. World Health Organization: New guidelines on antenatal care for a positive pregnancy experience, Sexual and reproductive health, Geneva, Switzerland: World Health Organization; 2016.

2. World Health Organization, UNICEF, UNFPA, World Bank Group and the United Nations Population Division: Trends in maternal mortality: 1990 to 2015. Geneva: World Health Organization; 2014.

3. Di Mario S: What is the effectiveness of antenatal care? (Supplement) Copenhagen, WHO Regional Office for Europe, 2005.

4. Bookari K, Yeatman H, Williamson M: Informing Nutrition Care in the Antenatal Period: Pregnant Women's Experiences and Need for Support, Biomed Res Int; 2017:4856527, 2017.

5. Yaya S, Bishwajit G, Ekholuenetale M, Shah V, Kadio B, Udenigwe O: Timing and adequate attendance of antenatal care visits among women in Ethiopia; 12(9):e0184934, 2017.

6. El-Zanaty F: Egypt Demographic and Health Survey 2014. Cairo, Egypt: Ministry of Health, El-Zanaty and Associates, and ICF International Rockville, Maryland, U.S.A, Ch. 3; 31-32, 2014.

7. Raghfar H, Khezri M, Vaeez Mahdavi Z, Sangri Mahzab K: Impact of health care system inefficiency in poverty of households. Hakim Journal; 16:9-18, 2012.

8. Sadeghi SK, Motefaker Azad M, Jalil Poor S: Factors affecting to the cost of health Private section and compare the impact of different income levels in Asian countries. Int J Soc Welf ; 14:55-75, 2012. 
9. Simkhada B, Teijlingen R, Porter M, and Simkhada P: Factors affecting the utilization of antenatal care in developing countries: Systematic review of literature. Journal of Advanced Nursing, 61 (3), 244-260, 2008.

10. Ye Y, Yoshida Y, Harun-Or-Rashid M, Sakamoto J: Factors affecting the utilization of antenatal care services among women in Kham District, Xiengkhouang province, Lao PDR, Nagoya J. Med. Sci. 72; 23 - 33, 2010.

11. El-Mahally AA, Amer NH, Nazif KM, Eid Eel-D, Abdel Kader HZ : Utilization of maternal health services offered by the Health Insurance Organization in Alexandria: J Egypt Public Health Assoc.; 72(3-4): 345-68. 1997.

12. Awadalla H, Kamel E, Mahfouz EM, Refaat TM: Evaluation of maternal and child health services in El-Minia City, Egypt, Journal of Public Health 17(5):321-329, 2009.

13. Ministry of Health and Population/Egypt, El-Zanaty and Associates/Egypt, and ICF International. 2014.

14. Hamed NA: Utilization pattern of antenatal care services among a group of women in Fayoum governorate, Master Thesis in Public Health, Faculty of Medicine, Fayoum University, 2014.

15. El-Gilany A, El-Wehady A, El-Wasify M: Updating and validation of the socioeconomic status scale for health research in Egypt, East Mediterr Health J. ;18(9):962-8, 2012.

16. Pandey S, Karki S: Socio-economic and Demographic Determinants of Antenatal Care Services Utilization in Central Nepal. Int $\mathbf{J}$ MCH AIDS ; 2(2):212-9. 2014.

17. Adhikari T, Sahu D, Nair S, Saha KB, Sharma RK, Pandey A: Factors associated with utilization of antenatal care services among tribal women: A study of selected States. Indian J Med Res; 144(1):58-66. 2016.

18. Dahiru T, Oche OM: Determinants of antenatal care, institutional delivery and postnatal care services utilization in Nigeria. Pan Afr Med J. 31; 21:321. 2015.

19. Graner S, Mogren I, Le DQ, Krantz G, Klingbert-Alvin $\mathrm{M}$ : Maternal health care professionals' perspectives on the provision and use of antenatal and delivery care: A qualitative descriptive study in rural Vietnam. BMC Public Health, 10, 608-618. 2010.
20. Malqvist M, Sohel N, Do TT, Eriksson L and Persson LA: Distance decay in delivery care utilization associated with neonatal mortality: A case referent study in Northern Vietnam. BMC Public Health, 10, 762-771, 2010.

21. Hamed NA: Utilization pattern of antenatal care services among a group of women in Fayoum governorate, Master Thesis in Public Health, Faculty of Medicine, Fayoum University, 2014.

22. Gupta A, Kumar P, Dorcas O: Decomposing the Socio-economic Inequalities in Utilization of Full Antenatal Care in Jharkhand State, India. International journal of population study, Vol 2, Issue 2, 92-106, 2017.

23. Babalola BI: Determinants of urban-rural differentials of antenatal care utilization in Nigeria. African Population Studies; 28(3):1263-1274, 2014.

24. Singh PK and Singh L: Examining InterGenerational Differentials in Maternal Health Care Service Utilization: Insights from the Indian Demographic and Health Survey, Journal of Biosocial Science, 46(3): 366385.2014.

25. Pell C, Menaca A, Were F, Afrah NA, Chatio S, Manda-Taylor L, Hamel MJ, Hodgson A, Tagbor H, Kalilani L, Ouma P, Pool R: Factors affecting antenatal care attendance: results from qualitative studies in Ghana, Kenya and Malawi. PLoS One;8(1):e53747.2013.

26. El- Shirbiny E, El Morsy A, El ghorory and El Ziny N: Assessment of Quality of antenatal care services in Beni-Suef governorate, thesis for master degree in public health, Cairo University, 2009.

27. Roy MP, Mohan U, Singh SK, Singh VK, Srivastava AK: Determinants of utilization of antenatal care services in rural Lucknow, India. J Fam Med Primary Care; 2:55-9, 2013.

28. Majrooh MA, Hasnain S, Akram J, Siddiqui A : A cross-sectional assessment of primary healthcare facilities for provision of antenatal care: calling for improvements in Basic Health Units in Punjab, Pakistan .Health Res Policy Syst. 25; 13 Suppl 1:59.2015.

29. Isatou K, Chou Y J, Liu T L and Nicole $\mathrm{H}$ : Women's perception of antenatal care 
services in public and private clinics in the Gambia International Journal for Quality in Health Care;10, 1-6, 2012.

30. Emelumadu OF, Onyeonoro UU, Ukegbu AU, Ezeama NN, CO, and Okezie OK: Perception of quality of maternal healthcare services among women utilizing antenatal services in selected primary health facilities in Anambra State, Southeast Nigeria, Niger Med J; 55(2): 148-155, 2014.
31. Saha KB, Singh N, Chatterjee SU, Roy J: Male involvement in reproductive health among scheduled tribe: experience from Khairwars of central India. Rural and Remote Health; 7(2):605. 2007.

32. Phillippi JC: Women's perceptions of access to prenatal care in the United States: a literature review. J Midwifery Women's Health. May-Jun; 54(3):219-25, 2009. 